\title{
Expression of junB is markedly stimulated by glycyrrhizin in a human hepatoma cell line
}

\author{
KATSURO KOIKE ${ }^{1,2,3}$ \\ ${ }^{1}$ Kitasato Institute for Life Sciences, Kitasato University, Shirokane, Minato-ku, Tokyo 108-8641; \\ ${ }^{2}$ The Cancer Institute (JFCR), Ariake, Koto-ku, Tokyo 135-8550, Japan
}

Received November 8, 2010; Accepted December 15, 2010

DOI: $10.3892 /$ or.2011.1137

\begin{abstract}
Effective therapeutic approaches for liver cancer are expected to be the prevention of chronic inflammation, progression of chronic liver injury to liver cancer and/or tumor cell growth by activating various oncogenes. Activation of the c-jun oncogene occurs in many cases at the early stage of transformation of chronic hepatitis into liver cancer. Accordingly, inhibition of c-jun gene function is thought to be important for the therapy of liver cancer. Although the junB gene has been identified as a c-jun-related gene, it acts as a tumor suppressor gene through competitive binding of JUNB with c-JUN. Therefore, alteration in junB gene expression in chronic hepatitis or liver cancer is an interesting target for the development of both therapeutic treatment and medicines. Monoammonium glycyrrhizinate (MAG) is used for the treatment of viral hepatitis or the prevention of chronic liver diseases. However, the mechanism by which MAG is involved in the suppression of oncogene function has not yet been characterized. In the present study, we first found that MAG highly stimulated JUNB expression in a human hepatoma cell line, HepG2. We examined the mechanism by which MAG increases junB gene expression by considering the previously published effects of MAG on the onset or development of chronic hepatitis or liver injury. The present data suggest that marked activation of junB expression leads to a pivotal role for MAG in multiple medical applications.
\end{abstract}

\section{Introduction}

Effective therapeutic approaches for hepatocellular carcinoma (HCC) are expected to be the prevention of chronic inflammation of virus-infected liver cells, malignant transformation of chronic liver injury and/or tumor cell growth by various

Correspondence to: Dr Katsuro Koike, ${ }^{3}$ Present address: Laboratory for Biomedicine, Kojimachi-Heights 205, 6-4 Kojimachi, Chiyoda-ku, Tokyo 102-0083, Japan

E-mail: koike-kat@ja2.so-net.ne.jp

Key words: junB gene activation, glycyrrhizin, junB mRNA, JUNB, signal transduction, promoter activity, human hepatoma cell line, tumor suppressor gene oncogenes. Activation of the c-jun oncogene occurs in many cases at the early stage of transformation of chronic hepatitis into HCC. Accordingly, it has been suggested that the inhibition of c-jun gene function is important for the prevention and therapy of virus-caused liver cancer (1).

The junB gene has been identified as c-jun related, but the junB gene behaves competitively in function among the jun family genes (2). The JUNB protein is a product of the junB gene and is assembled with other proteins, like FOS or RAF, to form the AP1 complex (activation protein 1). JUNB protein has a similar structure and function to that of the c-JUN protein (c-jun gene product) (3), but it lacks the JNK (c-jun $\mathrm{N}$-terminal kinase) binding site, thus could not be activated by JNK. Because of this property, JUNB hampers malignant cell growth by competitive binding with c-JUN (4), whereby junB gene acts as a tumor suppressor gene.

It has been reported that when the JUNB protein was increased in the cell, inflammation, virus infection and tumor cell growth were reduced (4-9). In another case, a junB genedefective knock-out mouse became lethal at 12.5-13.5 days of fetal development by hypoplastic placentation caused by anangioplasia (10). Thus, alteration in junB gene expression as well as its regulatory mechanism in chronic hepatitis or HCC could be an important target in developing both therapeutic treatment and medicines.

Glycyrrhizin (glycyrrhizic acid) extracted from the plant, Glycyrrhiza (11), and monoammonium glycyrrhizinate (MAG) are used as anti-inflammatory drugs for viral hepatitis or for the prevention of chronic liver diseases. Immunoregulatory activity of MAG has been reported in the regulation of $\mathrm{T}$ cell activation, induction of interferon, activation of NK cells, and the activation of extrathymic T lymphocyte differentiation $(12,13)$. MAG was also found to inhibit or inactivate viral growth and the survival time of mice infected with hepatitis virus was found to be elongated by administration of MAG. In another study, repression activity of MAG was reported in herpes virus replication and inactivation $(14,15)$.

MAG and anti-oxidization chemicals, such as $\mathrm{N}$-acetyl cysteine (NAC) and glutathione (GSH), are widely used for therapeutic treatment of liver toxicity or the prevention of chronic liver damage. However, in contrast to the case of NAC or GSH, at the molecular level, the mechanism by which MAG acts to suppress inflammation or is involved in the regulation of proto-oncogene and/or tumor suppressor gene remains obscure. 
In this study, we focused on the drug-induced activation of the junB gene as a tumor suppressor gene. Interestingly, we first found that MAG highly stimulated the expression of both junB mRNA and JUNB protein in a human hepatoma cell line, HepG2. Next, we analyzed the possible mechanism by which MAG increases junB gene expression by considering the previously published therapeutic effects of MAG on the onset or development of chronic hepatitis and liver cancer development. The present data strongly suggest that the activation of junB expression explains multiple roles of MAG in reducing inflammation, virus growth and liver carcinogenesis, as has been previously reported in the clinical literature (11-15).

\section{Materials and methods}

Therapeutic drugs and transcription inhibitors. Therapeutic drugs used in the interaction study with the junB gene were MAG and N-acetylcysteine (NAC) (both from Wako Pure Chemicals, Osaka Japan) at each concentration indicated in the figure legends. Transcription inhibitors used were: U0126 (ERK inhibitor) (16), SB203580 (p38 inhibitor) (both from Wako Pure Chemicals), JNKII (JNK inhibitor) (17), AG490 (JAK inhibitor) (18), and PKC inhibitor peptide (PKC inhibitor) (all from Calbiochem Merch-Biosciences, Tokyo Japan) in each indicated concentration, which was determined based on the previous reports of their IC50 values (50\% inhibitory concentration).

Cell line and culture conditions. Cell line HepG2 was derived from a human hepatoblastoma. Cells were cultured in the Dulbecco's modified Eagle's medium (DMEM: Nissui Pharmaceutical Co., Tokyo Japan) supplemented with $10 \%$ fetal bovine serum, $10 \%$ sodium bicarbonate, $60 \mu \mathrm{g} / \mathrm{ml}$ kanamycin and $8 \mathrm{mM}$ glutamine, using a $60-\mathrm{mm}$ culture dish or 24-well dish (Iwaki \& Co., Tokyo Japan) at $37^{\circ} \mathrm{C}$ in a $\mathrm{CO}_{2}$ incubator under $5 \% \mathrm{CO}_{2}(19)$.

Construction of plasmid vector DNA. junB DNA was amplified with junB primer sets (Takara Bio Inc., Otsu Shiga, Japan) (forward: ACCCCTACCGGAGTCTCAAA, reverse: GGAGTAGCTGCTGAGGTTGG) and custom-made human junB exon-primer sets (Operon Biotechnologies, Tokyo Japan), as summarized in Fig. 1 (forward: GAGCTGGAAC GCCTGATTGTC, reverse: TGGTTCATCTTGTGCAGAT CGTC) using the HotStar HiFidelity polymerase kit (Qiagen Inc., Balencia, CA, USA) and Human Genomic DNA (Roche Diagnostics K.K., Tokyo Japan) as the template.

Amplified DNA was separated by agarose gel electrophoresis and purified with a QIAquick gel extraction kit (Qiagen Inc.). Purified DNA was cloned with the pGEM-T easy Vector (Promega KK, Tokyo, Japan) and introduced into the DH5a competent cell (Promega KK). Plasmids were grown in LB Broth (Difco BD, NJ, USA) and purified in a GeneElute Plasmid Miniprep kit (Sigma-Aldrich Japan, Tokyo, Japan).

Real-time RT-PCR. junB DNA was amplified from cDNA by the Quantitect SYBR-Green PCR kit (Qiagen Inc.) and the amplified junB copy number was quantified using the junB primer set (Fig. 1; Takara Bio Inc.) prepared specifically for a real-time RT-PCR reaction. Amplified conditions used were $95^{\circ} \mathrm{C}$ for $15 \mathrm{~min}$ for the initial activation, followed by 30 cycles $\left(94^{\circ} \mathrm{C}\right.$ for $15 \mathrm{sec} ; 60^{\circ} \mathrm{C}$ for $25 \mathrm{sec}$; and $72^{\circ} \mathrm{C}$ for $\left.12 \mathrm{sec}\right)$, and melting curve analysis of the amplified sample was performed under the conditions of $95^{\circ} \mathrm{C}$ for $0 \mathrm{sec} ; 58^{\circ} \mathrm{C}$ for $15 \mathrm{sec}$; and $95^{\circ} \mathrm{C}$ for $0 \mathrm{sec}$, by increasing the temperature at intervals of $0.5^{\circ} \mathrm{C}$ from $58^{\circ} \mathrm{C}$. The same experiments as for junB were carried out with c-jun using the same cDNA sample with c-jun real-time PCR primer sets (Fig. 1; Takara Bio Inc.).

Quantification and normalization of amplified samples were performed using human GAPDH gene mRNA as the control with the LightCycler Faststart DNA Master SYBRGreen 1 (Roche Diagnostics K.K.) and the LightCyclerPrimer set human GAPDH (Roche Diagnostics K.K.). The human GAPDH (glyceraldehyde-3-phosphate dehydrogenase, acc. no. M33197.1) primer set consisted of, forward: AGCC ACATCGCTCAGACAC, and reverse: GCCCAATACGAC CAAATCC.

Luciferase assay. Cells were plated in 24-well dishes at the density of $5 \times 10^{4}$ cells/well, incubated for $18 \mathrm{~h}$ in $5 \% \mathrm{CO}_{2}$ atmosphere and subjected to transfection using the vector mixture, which was prepared as indicated below for $1 \mathrm{~h}$ in a $\mathrm{CO}_{2}$ incubator. Cells were then incubated for $48 \mathrm{~h}$ after the addition of serum containing DMEM medium. Vector mixture was prepared from serum-free DMEM medium containing $2.5 \mu \mathrm{g} / \mathrm{ml}$ test vector and $50 \mathrm{ng} / \mathrm{ml}$ of the internal control vector pLR-TK and three times its volume of Ribofection Tfx-20 Reagent (Promega KK).

After incubation, the drug was added to the wells and the cells were incubated for $6 \mathrm{~h}$, and then washed by PBS. Luciferase activity in the lysate was monitored using the Dual Luciferase assay system (Promega KK) following the manufacturer's protocol. Both luciferase activities in the cell lysates were measured by adding two luminescence reagents to the cell lysates, one for the test vector and another for the internal control vector.

Western blot analysis. Nuclear proteins were extracted from harvested cells using the Qproteome nuclear protein kit (Qiagen Inc.) and the protein concentration was measured by the BioRad protein assay (Bio-Rad Laboratories, Hercules CA, USA) (20). Next, 6X loading buffer (125 mM Tris- $\mathrm{HCl}$ pH $6.8,4 \%$ SDS, $10 \%$ DTT, $20 \%$ glycerol, $0.25 \%$ BPB) was added to each nuclear protein extract of $30 \mu \mathrm{g}$. Samples were denatured for $5 \mathrm{~min}$ at $100^{\circ} \mathrm{C}$, and subjected to SDS-PAGE (Bio-Rad Laboratories). After electroblotting of proteins onto a polyvinylidene difluoride membrane, the membranes were probed with anti-JUNB, anti-JUN and anti-SP1 primary antibodies (Santa Cruz Biotechnology Inc., Santa Cruz, CA, USA), followed by AP-conjugated anti-rabbit secondary antibodies (Santa Cruz Biotechnology Inc.). The membranes were then illuminated with BCIP/NBT solution (Wako Pure Chemicals).

\section{Results}

Expression of junB mRNA is highly increased by MAG treatment. To analyze how junB mRNA expression is affected 
A

\begin{tabular}{|c|l|l|c|}
\hline No. & \multicolumn{1}{|c|}{ Name } & \multicolumn{1}{|c|}{ Nucleotide sequence } & Tm \\
\hline 1 & junB RT-PCRstandard FW & ACCCCTACCGGAGTCTCAAA & 52.6 \\
\hline 2 & junB RT-PCRstandard RV & GGAGTAGCTGCTGAGGTTGG & \\
\hline 3 & humanjunBexon for RT-PCR FW & GAGCTGGAACGCCTGATTGTC & \multirow{2}{*}{54.4} \\
\hline 4 & humanjunBexon for RT-PCR RV & TGGTTCATCTTGTGCAGATCGTC & \multirow{2}{*}{55.4} \\
\hline 5 & c-jun RT-PCRstandard FW & CCTTGAAAGCTCAGAACTCG & \multirow{2}{*}{64.4} \\
\hline 6 & c-jun RT-PCRstandard RV & CCGACGGTCTCTCTTCAAAA & \\
\hline 7 & humanc-junexon for RT-PCR FW & GGGAACAGGTGGCACAGCTTA & \multirow{2}{*}{57} \\
\hline 8 & humanc-junexon for RT-PCR RV & GCAACTGCTGCGTTAGCATGA & \\
\hline 9 & hjunB3kbup FW & GCGATGATATCGAAGAGTGCCTAGCCCACAG & 63.5 \\
\hline 10 & hjunB3kbup RV & GCGATTAAGCTTATAGCTTTCCTGGCGTCGTT & \\
\hline 11 & hjunBDEL1 FW & GCGATTGATATCGAGGCTCTCTTCATCCTCCA & 63.5 \\
\hline 12 & hjunBDEL2 FW & GCGATTGATATCCCCCTCCTCACATGTCAACT & 63.5 \\
\hline 13 & hjunBDEL3 FW & GCGATTGATATCCACATACTGGGACCCTCACC & 63.5 \\
\hline 14 & hjunBDEL4 FW & GCGATTGATATCCACTTCCGTGGCTGACTAGC & 6 \\
\hline
\end{tabular}

B
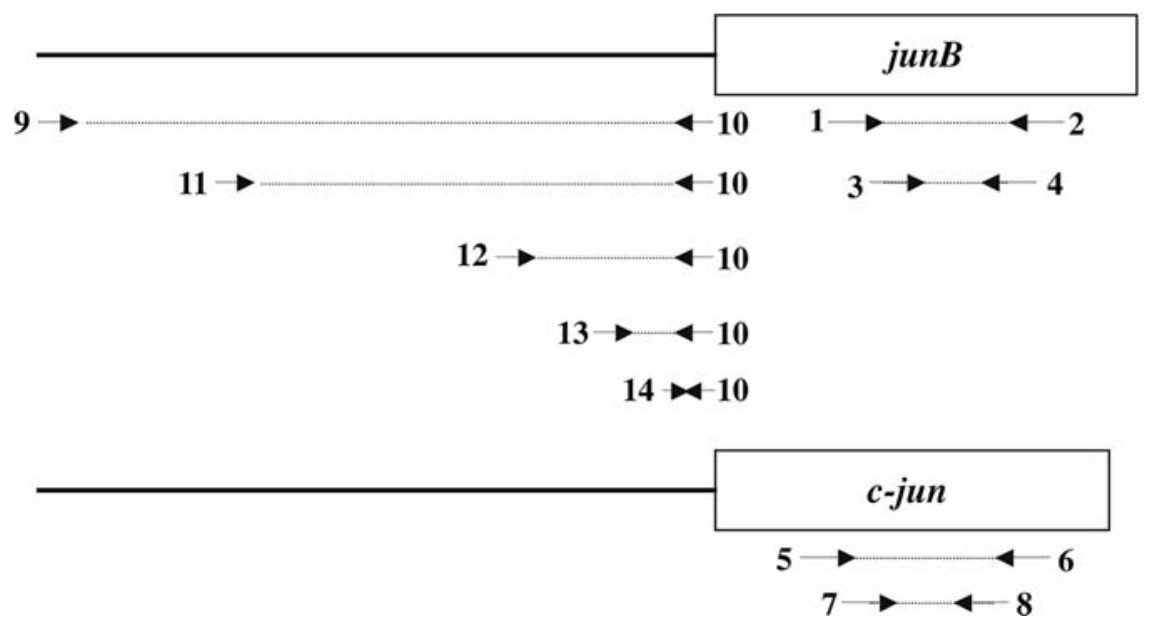

Figure 1. PCR primers and their location. (A) List of primers used in the experiments. (B) Set of primers and their location relative to the exon (open box) and upstream region (solid line) of the junB or c-jun gene. The number of each primer corresponds to the primer number in (A). Arrows indicate the direction of the extension reaction.

by MAG, HepG2 cells were treated with $10 \mathrm{mg}$ MAG in a DMEM/60-mm dish for $24 \mathrm{~h}$ and mRNA was extracted from the treated cells or untreated control cells, and then subjected to real-time RT-PCR analysis for copy number detection. A $>5$-fold increase in junB mRNA expression was observed in MAG-treated cells as compared to the untreated cells. When the same samples were subjected to c-jun mRNA expression analysis, the level of c-jun mRNA in MAG-treated cells exhibited a roughly 2 -fold increase (Fig. 2A).

As previous literature has indicated that NAC activates the ERK kinase cascade (21) and that junB gene expression is activated by ERK (22), the effect of NAC on junB mRNA expression was examined as a reference. A roughly 2-fold increase in junB mRNA expression was observed in cells treated with $10 \mathrm{mM} \mathrm{NAC}$ or $5 \mathrm{mM} \mathrm{GSH}$ as compared to the control, but this was not observed in c-jun gene expression (Fig. 2B). As will be seen later, NAC activation of junB mRNA was counteracted by the ERK inhibitor.

JUNB protein is highly increased in the presence of MAG. Nuclear proteins were extracted from cells treated with MAG and the expression of both JUNB and c-JUN proteins was studied by Western blot analysis. Data clearly showed a marked increase in JUNB expression in the presence of MAG, while c-JUN expression exhibited no increase as compared to the control. There also was no increase in SP1 expression, as shown in Fig. 3A. Some other proteins, FOS, NF-кB, JUND etc., were examined, but no significant increase was observed in their expression (data not shown). In addition, the effect of NAC on JUNB protein expression was also examined in the presence of $10 \mathrm{mM}$ NAC. Nuclear extracts from $10 \mathrm{mM}$ NAC-treated and untreated cells were analyzed, however, an increase in JUNB protein expression was not detected in NAC-treated cells as compared to the untreated cells. There was no increase in c-JUN or SP1 protein expression as compared to the control (Fig. 3B).

Signal transduction cascade encourages MAG activation of junB gene expression. To identify which signal transduction cascade is targeted by MAG in the case of junB gene expression, junB mRNA expression was monitored in the presence of a specific inhibitor of the signal transduction cascade after 
A

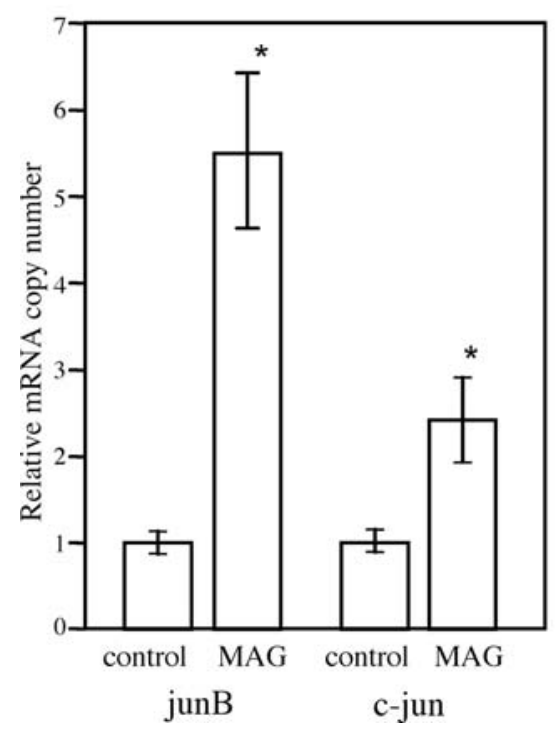

B

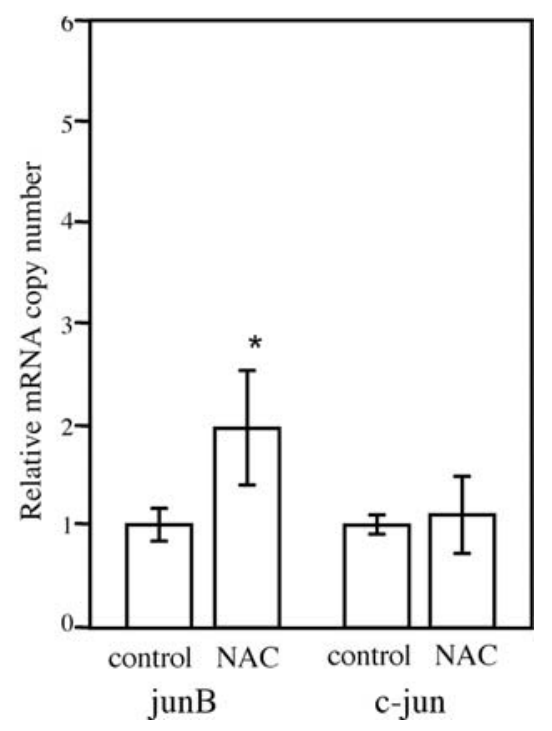

Figure 2. Expression of junB mRNA in the presence of MAG or NAC. HepG2 cells were plated in a 60 -mm dish at the density of $1 \times 10^{6}$ cells/dish, incubated for $18 \mathrm{~h}$ and further incubated for $24 \mathrm{~h}$ in a fresh medium supplemented with or without $10 \mathrm{mg}$ MAG/dish (A) or $10 \mathrm{mM}$ NAC (B). First-strand cDNA was prepared directly from cell lysate without RNA purification using the RNeasy mini kit (Qiagen Inc.) and the FastLane Cell cDNA kit (Qiagen Inc.). The copy number of junB mRNA was obtained by real-time RT-PCR and calibrated taking the copy number of the internal standard GAPDH mRNA in the control as 1.0. The data represent the mean \pm standard deviations (SD) of at least three independent experiments. ${ }^{*} \mathrm{P}<0.05$ versus control.

A

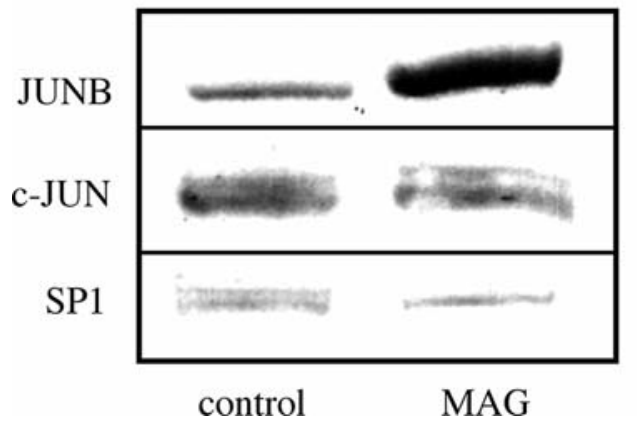

B

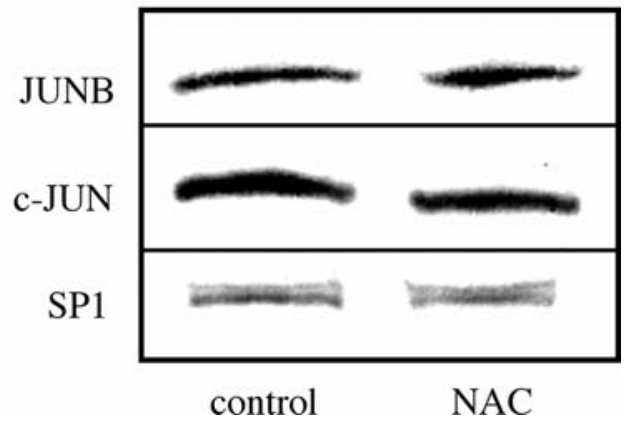

Figure 3. Expression of JUNB protein in the presence of MAG or NAC. Cells were plated at the density of $1 \times 10^{6}$ cells $/ 60$-mm dish and incubated for $18 \mathrm{~h}$. Cells were further cultured in a fresh medium supplemented with $10 \mathrm{mg}$ MAG/dish (A) or $10 \mathrm{mM}$ NAC (B) for $24 \mathrm{~h}$, washed with ice-cold PBS twice and harvested in PBS with a rubber policeman. Nuclear proteins were then extracted from the cell pellets and subjected to Western blot analysis.

the addition of MAG. Inhibitors used were UO126 for ERK, SB102538 for p38, JUK11 for JNK, AG490 for JAK and peptide inhibitor for PKC.

Expression of junB mRNA was investigated in the presence or absence of each inhibitor in the MAG-treated or control HepG2 cells. Results indicated that MAG-induced expression of junB mRNA was not blocked by the addition of any inhibitor (Fig. 4). The results suggested that MAG activation of junB gene expression occurs through a different pathway from that of the signal transduction cascades described above.

As a control experiment, analysis of junB mRNA expression was carried out in the presence or absence of each signal transduction cascade inhibitor using NAC-treated or -untreated cells. When the extracted mRNA was subjected to real-time PCR analysis, the ERK inhibitor, UO126 suppressed NAC- induced increase of junB mRNA (Fig. 5A). However, no other inhibitors exhibited their inhibitory effects on NACinduced junB mRNA (Fig. 5B and C). The present data are consistent with the previous observation, in which NAC activation of junB gene expression was due to involvement of the ERK kinase cascade $(23,24)$.

Analysis of the human junB gene promoter region. To understand the mechanism of human junB gene regulation by MAG, we focused on the 5-kb upstream region containing the enhancer and core promoter sequences of the mouse junB gene, which are well-characterized. The 5-kb upstream sequences of the mouse junB gene were obtained from Ensemble Genome Browser (25) and their homology with the human junB gene was searched using VISTA (26) analysis. High-sequence homology was detected within a 
A

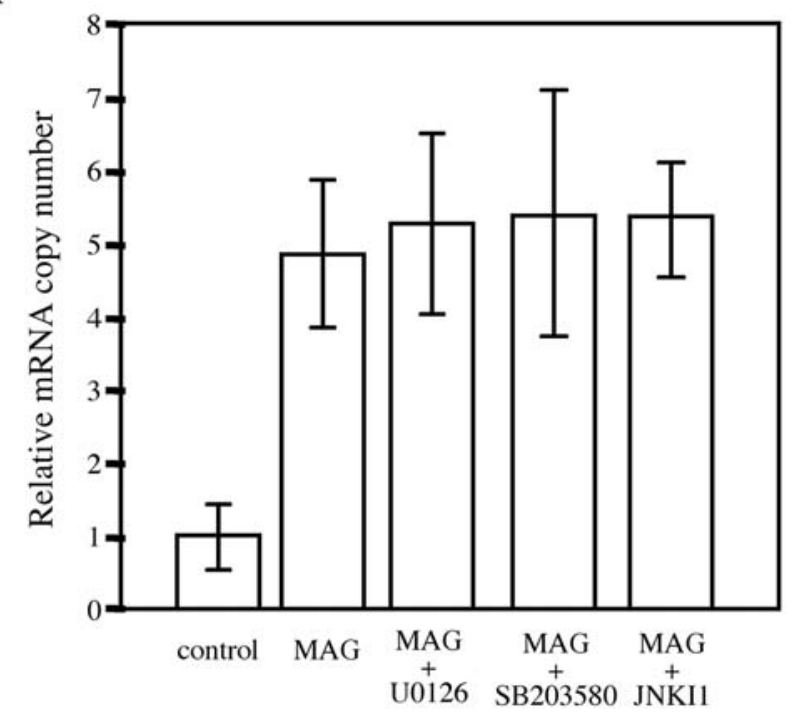

B

$\mathrm{C}$
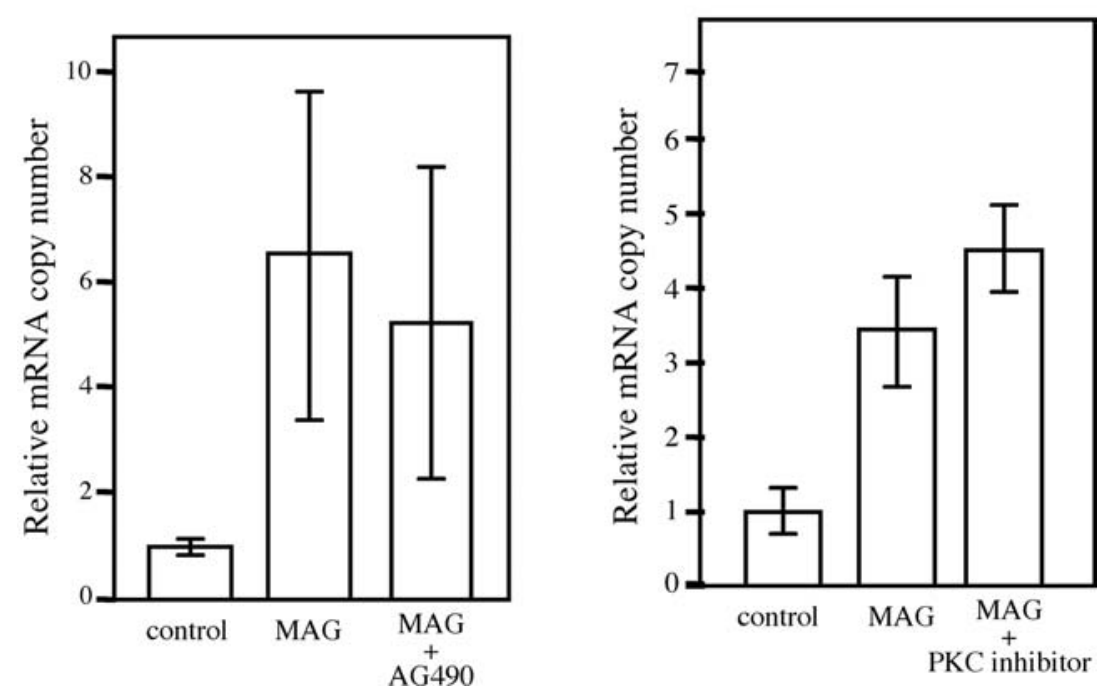

Figure 4. Effect of inhibitor on junB mRNA expression in the presence of MAG. Cells were plated at the density of $1 \times 10^{6}$ cells/60-mm dish and incubated for $18 \mathrm{~h}$, and further cultured in the presence or absence of MAG with or without MAPK inhibitors (A), JAK inhibitor (B) or PKC inhibitor (C). Expression of junB mRNA is examined as described in the legend of Fig. 2. The data represent the mean $\pm \mathrm{SD}$ of at least three independent experiments. ${ }^{*}<0.05$ versus control.

3-kb upstream region of the human junB gene, but there was no significant homology in the 3-5-kb upstream sequences, as was previously described (Fig. 6A) $(27,28)$. This 3-kb upstream region was therefore amplified by PCR and introduced into the pGL4 luciferase vector. The fusion vector (named $3 \mathrm{kbUP}$ vector) was then transfected to HepG2 cells at concentrations of $0.25-2 \mu \mathrm{g}$ of $3 \mathrm{kbUP}$ vector $\mathrm{DNA} / \mathrm{ml}$, and promoter activity of the transfected DNA was assayed. Strong luciferase activity was detected in a concentration-dependent manner, indicating that the promoter-enhancer activity was located within the $3-\mathrm{kb}$ upstream region of the human junB gene (Fig. 6A), similar to the mouse junB gene $(27,28)$.

In addition to the $3 \mathrm{kbUP}$ vector, four mutant vectors that contained upstream 2.5-kb (del1), 1-kb (del2), 0.5-kb (del3) and 150-bp (del4) sequences were constructed and transfected to cells at the concentration of $0.5 \mu \mathrm{g}$ DNA/well, and the promoter activities were examined using a dual luciferase assay. Results indicated that del1 and del 2 mutants showed a slightly higher activity than that of the $3 \mathrm{kbUP}$ vector and that luciferase activity was then decreased according to reduction of the enhancer region (Fig. 6B). The present data are consistent with previous observations, in which SRE2 was found to be present between an upstream 3.0-2.5-kb region and exhibited a negative effect on promoter activity $(27,28)$. Furthermore, it is clear that the del4 mutant containing a 150-bp upstream region showed significant promoter activity as compared to that of the control vector without a $150-b p$ upstream region (Fig. 6C), which corresponds to the core promoter region of the junB gene $(27,28)$, where the IL6responsive element and TATA box are located (29).

To investigate whether MAG-induced junB mRNA expression was dependent on the junB promoter region or not, 
A

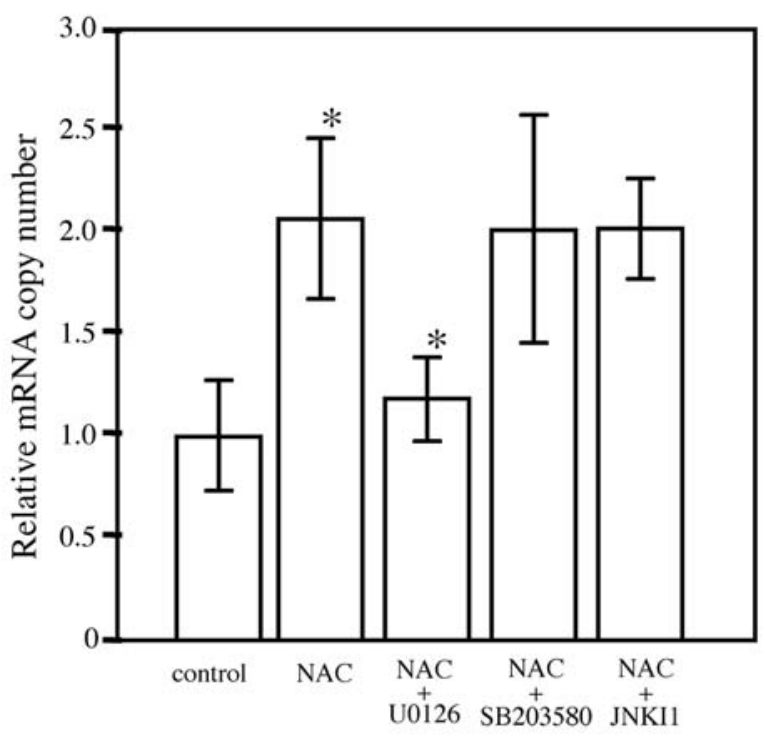

B

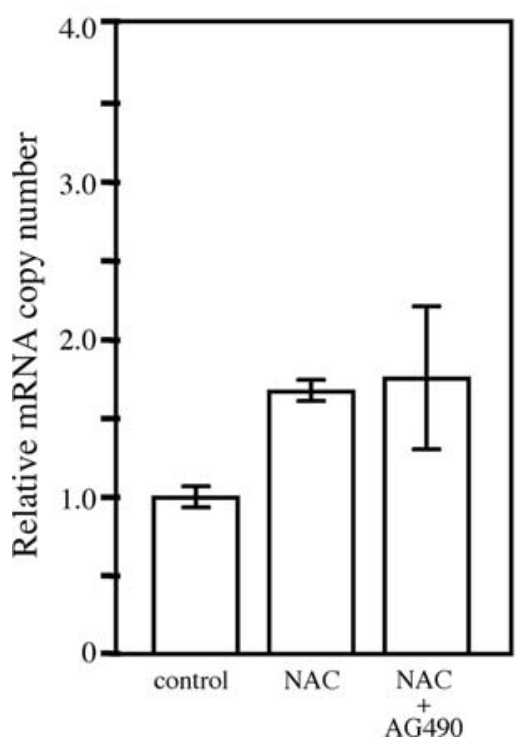

C

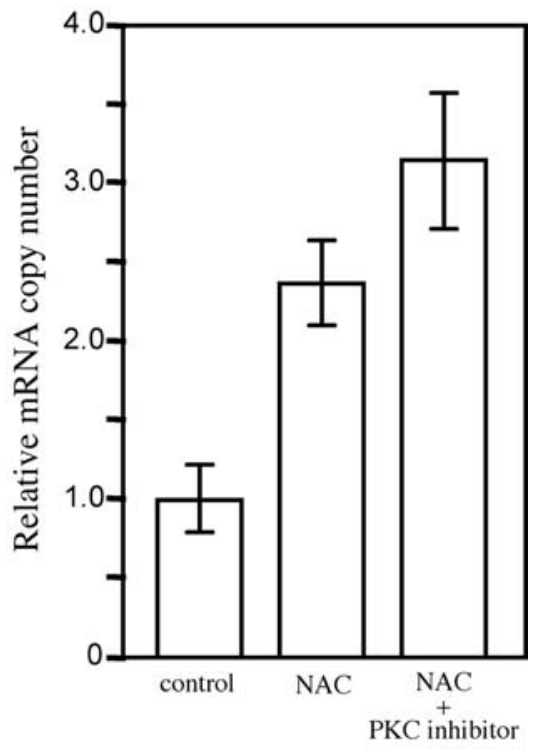

Figure 5. Effect of inhibitor on junB mRNA expression in the presence of NAC. Cells were plated at the density of $1 \times 10^{6}$ cells/60-mm dish and incubated for $18 \mathrm{~h}$, and further cultured in the presence or absence of $10 \mathrm{mM}$ NAC with or without MAPK inhibitors (A), JAK inhibitor (B) or PKC inhibitor (C). Expression of junB mRNA was examined, as described in the legend of Fig. 2. The data represent the mean $\pm \mathrm{SD}$. $\mathrm{P}<0.05$ versus control.

luciferase activity of $3 \mathrm{kbUP}$ or the deletion vector-transfected cells was examined in the presence of MAG. Results indicated that luciferase activity was not increased by MAG in the case of $3 \mathrm{kbUP}$ and luciferase activity was rather decreased by MAG, when compared to the control (Fig. 6D). Activity assay was also carried out using del2- or del3- vector, but the promoter activity was not changed by MAG treatment (data not shown). The present observations indicated that expression of the endogenous junB gene was increased by MAG, but it was not the case in the exogenously introduced luciferase system. One explanation may be an absence of the chromatin structure in the enhancer region in the $3.0-2.5-\mathrm{kb}$ upstream region of the junB gene in the exogenously transfected DNA vector (30). The chromatin structure of the upstream 3.0-2.5-kb region containing the SRE2-responsible element may play an important role in the activation of endogenous junB gene expression by MAG.

On the other hand, we examined the NAC effect on the promoter activity using 3-kb UP or the deletion mutant vector. Luciferase activity of 3-kb UP was found to be increased by NAC (Fig. 6E). Luciferase activity of the deletion mutant, except for the del4 mutant, was also increased by NAC. The present data are consistent with the previous observations indicating that the NAC-responsible element was present in a 500-150-bp region, where the Ets-binding and CRE-like sites were located $(27,28)$. 
A

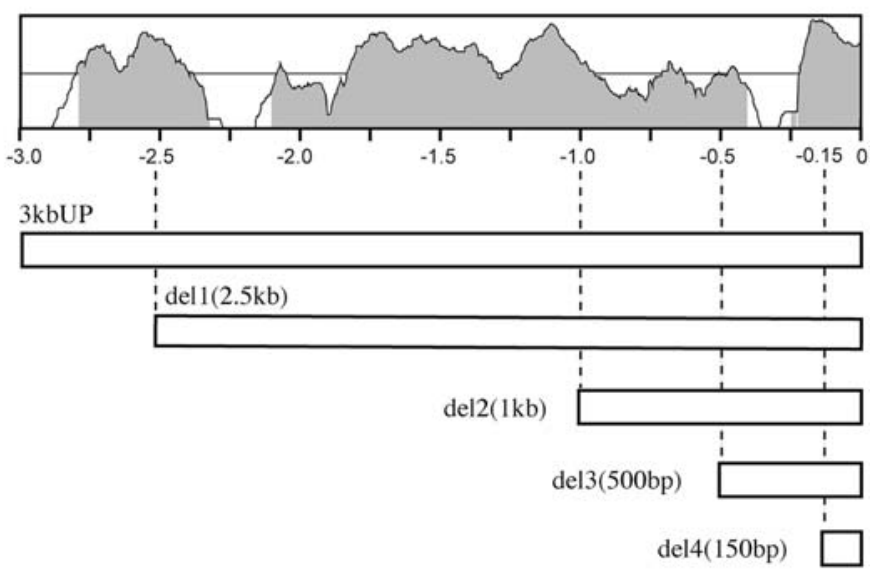

B

$\mathrm{C}$
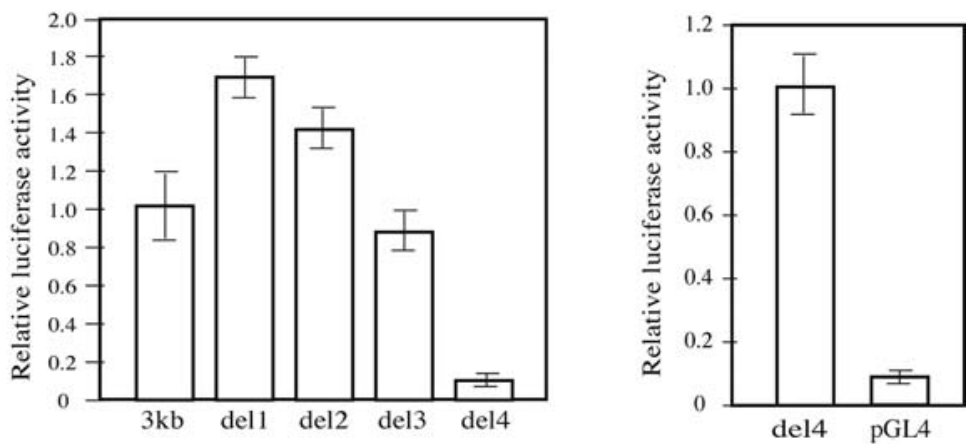

D

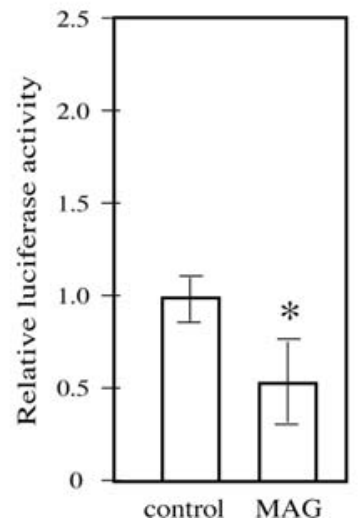

$\mathrm{E}$

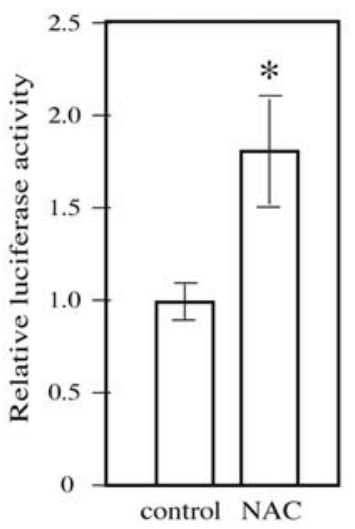

Figure 6. Promoter activity analysis of the 3-kb upstream region in the junB gene. (A) Schematic presentation of the 3kbUP vector and deletion mutants in the junB gene promoter region. Shaded region indicates homology between mouse and human junB genes. For construction of the plasmid vector DNA containing the promoter region of the junB gene, a 3-kb upstream region of junB DNA was amplified by a PCR reaction using the junB primer set (Fig. 1A; Operon Biotechnologies) that was designed to introduce the EcoRV site at the 5'end and HindIII site at the 3' end of the target DNA. Amplified DNA was purified with the QIAquick gel extraction kit after separation by agarose gel electrophoresis. Purified DNA and luciferase vector pGL4.12 (luc2CP; Promega KK) were subjected to restriction enzyme digestion with EcoRV and HindIII, followed by purification with the QIAquick PCR purification kit (Qiagen Inc.) and the plasmid vector DNA was constructed using the DNA ligation kit (Takara Bio Inc.). Plasmid vector DNAs were then introduced into DH5a competent cells and cultivated in LB Broth (Difco BD) before purification with Plasmid maxi kit (Qiagen Inc.). Mutant vector that contained upstream 2.5-kb (del1), 1-kb (del2), 0.5-kb (del3) or 150-bp (del4) was constructed, as described above, and transfected to cells at the concentration of $0.5 \mu \mathrm{g}$ DNA/well. (B) Relative promoter activity of deletion mutants. (C) Promoter activity of the del4 mutant or a vector without the upstream region of the junB gene. Vertical axis of (B) or (C) shows the relative promoter activity of the $3 \mathrm{kbUP}$ or the del4 mutant as 1.0 , respectively, after calibration of promoter activity using the pLR-TK control vector. Data represent the mean \pm SD of at least three independent experiments. (D) Promoter activity of the 3-kb upstream region in the presence of $1 \mathrm{mg} /$ well MAG. Vertical axis shows the relative promoter activity of 3-kb UP as 1.0 after calibration of promoter activity using the pLR-TK control vector. (E) Promoter activity in the presence of $10 \mathrm{mM} \mathrm{NAC}$. Vertical axis shows the relative promoter activity, as described in (D). The data represent the mean $\pm \mathrm{SD}$ of five independent experiments. ${ }^{*} \mathrm{P}<0.05$ versus control.

\section{Discussion}

The junB gene exhibits multiple functions; for instance, the anti-inflammatory effect of the junB gene product has been reported in psoriatic erythroderma, a form of dermatopathy, as junB gene expression was found to be decreased in the affected part (31). In the case of mouse skin, inflammation was induced by down-regulation of junB gene expression 
(32). These facts suggested that liver carcinogenesis could be prevented, if junB gene expression can be activated in chronic hepatitis (33).

JUNB forms the AP1 complex with a transcription factor like FOS and is involved in cell cycle regulation as a regulatory factor. The AP1 complex with JUNB activates p16 and down-regulates cyclin D1, thereby causing suppression of G1-to-S transition and the inhibition of cell growth $(34,35)$. So far, TAK1, SRE1 binding protein, c-Ets and IL6 have been reported as activators of junB gene expression. These factors are involved in junB gene expression via MAP kinase pathways like p38, and ERK or via the JAK/STAT pathway $(22,27,28,36-44)$. A previous report verified that p38 was activated by various stress conditions, such as osmotic stimulus or cytokine, suggesting its relationship to cell death (45-49). ERK induced cell growth and differentiation and regulated cell cycle transition (50-52). JAK/STAT was activated by a free radical and/or IL6 (53-55).

As it has not yet been reported how MAG interacts with junB activating factors, we firstly focused on the reported result that MAG amplified the IL12 molecule, which is known to have anticancer action via the NF- $\mathrm{NB}$ transcription pathway (56). Although NF-кB is activated in cancer cells, improvement of the immune system and enhancement of junB gene expression have been reported (57). However, the therapeutic effect of drugs on the activation of junB gene expression in liver carcinogenesis has not been reported previously. In this study, we first demonstrated that MAG had a specific stimulatory effect on junB gene expression in HepG2 cells. We then examined a possible mechanism of MAG action using inhibitors for signal transduction cascades (58).

Based on the observation that MAG-induced expression of mRNA was much higher for the junB gene than the c-jun gene and that the functional level of JUNB protein was much higher than that of c-JUN, the role of MAG would most likely be the suppression of AP-1 function. Studies with five inhibitors of different signaling cascades revealed no influence on the MAG-induced activation of junB mRNA expression. From these observations, MAG activation of endogenous junB gene expression is predicted to be dependent on other signaling pathways than signaling cascades, such as MAP kinase, JAK/STAT and PKC cascades (56-58).

Promoter-enhancer activity assay using the 3-kb UP region of the junB gene or its deletion mutants, revealed that del1 and del2 deletion mutants showed higher activity than that of 3kbUP-transfected cells. Mutant del4 showed lower activity because of the length of the inserted enhancer region. The present results suggested that binding site(s) for an inhibitory factor and/or SRE2(27) of the junB gene exist within an upstream 3-2.5-kb region (27) and that binding sites for other factors, such as SRE1, CRE-like and STAT family proteins etc., are situated within an upstream 2.5-kb region (28).

Expression of endogenous junB gene is increased by MAG, but not in an exogenously introduced expression system. Activity of the del 2 mutant was found to be unchanged in the presence of MAG. Furthermore, the core promoter activity of del4, del3 or del 2 was not changed at all by MAG. Considering the result that MAG activated endogenous junB mRNA expression, it is less probable that MAG affects the 2.5-kb region and increases junB gene expression. According to the previous and present observations, the NAC responsive site is located within a 500-bp upstream region, in which the level of promoter activity and mRNA expression were parallel, and the MAG responsive region may be located further upstream in the $2.5-3-\mathrm{kb}$ region. The structure of exogenously introduced junB DNA fused to the luciferase gene was different from the chromatin structure of the endogenous gene (30). Transfected 3-kb UP DNA in the junB gene would not sustain the chromatin structure of MAG interaction site in cells.

Lastly, it should be emphasized that MAG clearly activates junB gene expression as seen in both the mRNA and protein levels in the present study, although the mechanism by which MAG increases the amount of mRNA has not yet been clarified. Marked stimulation of junB gene expression may explain the multiple pharmacological effects of MAG described in the previous clinical literature (11-15). Further experiments are needed to clarify the mechanism of stimulation by MAG of cellular junB gene expression.

\section{Acknowledgements}

Appreciation is expressed to Ms. N. Kaneniwa and Mr. T. Konno for their technical assistance, to Dr J. MizushimaSugano for her technical advice, and also to Ms. M. Kobayashi for her preparation of the figures. This research was supported partly by a grant from the Ministry of Education, Sports, Science and Technology, Japan.

\section{References}

1. Eferl R, Ricci R, Kenner L, et al: Liver tumor development. c-Jun antagonizes the proapoptotic activity of p53. Cell 112: 181-192, 2003.

2. Vogt PK: Fortuitous convergences: The beginnings of JUN. Nat Rev Cancer 2: 465-469, 2002.

3. Passegue E, Jochum W, Behrens A, Ricci R and Wagner EF: JunB can substitute for Jun in mouse development and cell proliferation. Nat Genet 30: 158-166, 2002.

4. Shaulian E and Karin M: AP-1 in cell proliferation and survival. Oncogene 20: 2390-2400, 2001.

5. Jochum W, Passegue E and Wagner EF: AP-1 in mouse development and tumorigenesis. Oncogene 20: 2401-2412, 2001.

6. Wagner EF: AP-1 introductory remarks. Oncogene 20: 2334-2335, 2001

7. Shaulian E and Karin M: AP-1 as a regulator of cell life and death. Nat Cell Biol 4: 131-136, 2002.

8. Eferl R and Wagner EF: AP-1: a double-edged sword in tumorigenesis. Cancer 3: 859-868, 2003.

9. Zenz R and Wagner EF: Jun signalling in the epidermis: From developmental defects to psoriasis and skin tumors. Int J Biochem Cell Biol 38: 1043-1049, 2006.

10. Kenner L, Hoebertz A, Beil T, et al: Mice lacking JunB are osteopenic due to cell-autonomous osteoblast and osteoclast defects. J Cell Biol 164: 613-623, 2004.

11. Suzuki H, Ohta Y, Takino T, Fujisawa K and Hirayama C: Effects of glycyrrhizin on biochemical tests in patients with chronic hepatitis-double blind trial. Asian Med J 26: 423-438, 1983.

12. Zhang $\mathrm{YH}$, Isobe $\mathrm{K}$, Iwamoto $\mathrm{T}$ and Nakashima I: Bidirectional control by glycyrrhizin of the growth response of lymphocytes stimulated through a receptor-bypassed pathway. Immunol Lett 32: 147-152, 1992.

13. Kimura M, Watanabe $\mathrm{H}$ and Abo T: Selective activation of extrathymic $\mathrm{T}$ cells in the liver by glycyrrhizin. Biotherapy 5 : 167-176, 1992.

14. Pompei R, Flore O, Marccialis MA, Pani A and Loddo B: Glycyrrhizic acid inhibits virus growth and inactivates virus particles. Nature 281: 689-690, 1979. 
15. Baba M and Shigeta S: Antiviral activity of glycyrrhizin against varicella-zoster virus in vitro. Antiviral Res 7: 99-107, 1987.

16. Favata MF, Horiuchi KY, Manos EJ, et al: Identification of a novel inhibitor of mitogen-activated protein kinase. J Biol Chem 273: 18623-18632, 1998.

17. Qadri I, Iwahashi M, Capasso JM, et al: Induced oxidative stress and activated expression of manganese superoxide dismutase during hepatitis C virus replication: Role of JNK, p38 MAPK and AP-1. Biochem J 378: 919-928, 2004.

18. Huang C, Cao J, Huang KJ, et al: Inhibition of STAT3 activity with AG490 decreases the invasion of human pancreatic cancer cells in vitro. Cancer Sci 97: 1417-1423, 2006.

19. Shirakata Y and Koike K: Hepatitis B virus X protein induces cell death by causing loss of mitochondrial membrane potential J Biol Chem 278: 22071-22078, 2003

20. Guo L, Guo Y, Xiao S and Shi X: Protein kinase p-JNK is correlated with the activation of AP-1 and its associated Jun family proteins in hepatocellular carcinoma. Life Sci 77: 1869-1878, 2005.

21. Deshpande VS and Kehrer JP: Mechanisms of N-acetylcysteinedriven enhancement of MK886-induced apoptosis. Cell Biol Toxicol 22: 303-311, 2006

22. Watanabe M, Sasaki M, Itoh K, et al: JunB induced by constitutive CD30-extracellular signal-regulated kinase 1/2 mitogen-activated protein kinase signalling activates the CD30 promoter in anaplastic large cell lymphoma and reed-sternberg cells of Hodgkin lymphoma. Cancer Res 65: 7628-7634, 2005.

23. Rao GN, Katki KA, Madamanchi NR, Wu Yand Birrer MJ JunB forms the majority of the AP- 1 complex and is a target for redox regulation by receptor tyrosine kinase and $\mathrm{G}$ proteincoupled receptor agonists in smooth muscle cells. J Biol Chem 274: 6003-6010, 1999.

24. Lin CH, Kuo SC, Huang LJ and Gean PW: Neuroprotective effect of $\mathrm{N}$-acetylcysteine on neuronal apoptosis induced by a synthetic gingerdione compound: involvement of ERK and p38 phosphorylation. J Neurosci Res 84: 1485-1494, 2006.

25. http://www.ensembl.org/index.html

26. http://genome.lbl.gov/vista/index.shtml

27. Kitabayashi I, Kawakami Z, Matsuoka T, Chiu R, Gachelin G and Yokoyama K: Two cis-regulatory elements that mediate different signaling pathways for serum-dependent activation of the junB gene. J Biol Chem 268: 14482-14489, 1993.

28. Nakajima K, Kusafuka T, Takeda T, Fujitani Y, Nakae K and Hirano T: Identification of a novel interleukin- 6 response element containing an Ets-binding site and a CRE-like site in the junB promoter. Mol Cell Biol 13: 3027-3041, 1993

29. Sjin RM, Krishnaaraju K, Hoffman B and Liebermann DA Transcriptional regulation of myeloid differentiation primary response $(\mathrm{MyD})$ genes during myeloid differentiation is mediated by nuclear factor Y. Blood 100: 80-88, 2002.

30. Harris HE and Andersson U: The nuclear protein HMGB1 as a proinflammatory mediator. Eur J Immunol 34: 1503-1512, 2004

31. Ritchlin C and Tausk F: A medical conundrum: onset of psoriasis in patients receiving anti-tumour necrosis factor agents. Ann Rheum Dis 65: 1541-1544, 2006.

32. Meixner A, Zenz R, Schonthaler HB, Kenner L, Scheuch H, Penninger JM and Wagner EF: Epidermal JunB represses GCSF transcription and affects hematopoiesis and bone formation. Nat Cell Biol 8: 1003-1011, 2008

33. Zenz R, Eferl R, Kenner L, et al: Psoriasis-like skin disease and arthritis caused by inducible epidermal deletion of Jun proteins. Nature 437: 369-375, 2005.

34. Bakiri L, Lallemand D, Bossy-Wetzel E and Yaniv M: Cell cycle-dependent variations in C-Jun and JunB phosphorylation:a role in the control of cyclin D1 expression. EMBO J 19: 2056-2068, 2000 .

35. Cook SJ, Aziz N and McMahon M: The repertoire of Fos and Jun protein expressed during the G1 phase of the cell cycle is determined by the duration of mitogen-activated protein kinase activation. Mol Cell Bio 19: 330-341, 1999.

36. Apel I, Yu CL, Wang T, et al: Regulation of the junB gene by v-src. Mol Cell Biol 12: 3356-3364, 1992

37. Baumann H, Marinkovic-Pajovic S, Won KA, et al: The action of interleukin 6 and leukaemia inhibitory factor on liver cells. Ciba Found Symp 167: 100-114, 1992

38. Coffer P, de Jonge M, Mettouchi A, Binetruy B, Ghysdael J and Kruijer W: junB promoter regulation: Ras mediated transactivation by c-Ets-1 and c-Ets-2. Oncogene 9: 911-921, 1994.
39. Coffer P, Lutticken C, van Puijenbroek A, Klop-de Jonge M, Horn $\mathrm{F}$ and Kruijer W: Transcriptional regulation of the junB promoter: analysis of STAT-mediated signal transduction. Oncogene 10: 985-994, 1995.

40. Eggen BJ, Benus GF, Folkertsma S, Jonk LJ and Kruijer W: TAK1 activation of the mouse JunB promoter is mediated through a CCAAT box and NF-Y. FEBS Lett 506: 267-271, 2001.

41. Finch JS, Rosenberger SF, Martinez JD and Bowden GT: Okadaic acid induces transcription of junB through a CCAAT box and NF-Y. Gene 267: 135-144, 2001

42. Przybyla-Zawislak BD, Kim CS, Ali SF, Slikker W Jr and Binienda ZK: The differential JunB responses to inhibition of succinate dehydrogenase in rat hippocampus and liver. Neurosci Lett 381: 354-357, 2005

43. Bernt C, Vennegeerts T, Beuers U and Rust C: The human transcription factor AP-1 is a mediator of bile acid-induced liver cell apoptosis. Biochem Biophys Res Commun 340: 800-806, 2006.

44. Chalmers CJ, Gilley R, March HN, Balmanno K and Cook SJ: The duration of ERK1/2 activity determines the activation of c-Fos and Fra-1 and the composition and quantitative transcriptional output of AP-1. Cell Signal 19: 695-704, 2007.

45. Nadkarni V, Gabbay KH, Bohren KM and Sheikh-Hamad D: Osmotic response element enhancer activity. Regulation through p38 kinase and mitogen-activated extracellular signal-regulated kinase kinase. J Biol Chem 274: 20185-20190, 1999.

46. Swart JM, Bergeron DM and Chiles TC: Identification of a membrane Ig-induced p38 mitogen-activated protein kinase module that regulates cAMP response element binding protein phosphorylation and transcriptional activation in $\mathrm{CH} 31 \mathrm{~B}$ cell lymphomas. J Immunol 164: 2311-2319, 2000.

47. Schrantz N, Bourgeade MF, Mouhamad S, Leca G, Sharma S and Vazquez A: p38-mediated regulation of an Fas-associated death domain protein-independent pathway leading to caspase- 8 activation during TGFbeta-induced apoptosis in human Burkitt lymphoma B cells BL41. Mol Biol Cell 12: 3139-3151, 2001.

48. Tarn C, Lee S, Hu Y, Ashendel C and Andrisani OM: Hepatitis $B$ virus $X$ protein differentially activates RAS-RAF-MAPK and JNK pathways in X-transforming versus non-transforming AML12 hepatocytes. J Biol Chem 276: 34671-34680, 2001

49. Wang WH, Gregori G, Hullinger RL and Andrisani OM: Sustained activation of p38 mitogen-activated protein kinase and c-Jun $\mathrm{N}$-terminal kinase pathways by hepatitis $\mathrm{B}$ virus $\mathrm{X}$ protein mediates apoptosis via induction of Fas/FasL and tumor necrosis factor (TNF) receptor $1 / \mathrm{TNF}$-alpha expression. Mol Cell Biol 24: 10352-10365, 2004.

50. Robinson MJ and Cobb MH: Mitogen-activated protein kinase pathways. Curr Opin Cell Biol 9: 180-186, 1997.

51. Schaeffer HJ and Weber MJ: Mitogen-activated protein kinases: specific messages from ubiquitous messengers. Mol Cell Biol 19: 2435-2444, 1999 .

52. Nijhara R, Jana SS, Goswami SK, Rana A, Majumdar SS, Kumar V and Sarkar DP: Sustained activation of mitogenactivated protein kinases and activator protein 1 by the hepatitis $\mathrm{B}$ virus $\mathrm{X}$ protein in mouse hepatocytes in vivo. J Virol 75: 10348-10358, 2001.

53. Simon AR, Rai U, Fanburg BL and Cochran BH: Activation of the JAK-STAT pathway by reactive oxygen species. Am J Physiol 275: 1640-1652, 1998.

54. Heinrich PC, Behrmann I, Haan S, Hermanns HM, MullerNewen G and Schaper F: Principles of interleukin (IL)-6-type cytokine signalling and its regulation. Biochem J 374: 1-20, 2003.

55. Zauberman A, Zipori D, Krupsky M and Ben-Levy R: Stress activated protein kinase p38 is involved in IL-6 induced transcriptional activation of STAT3. Oncogene 18: 3886-3893, 1999.

56. Dai JH, Iwatani Y, Ishida T, et al: Glycyrrhizin enhances interleukin-12 production in peritoneal macrophages. Immunology 103: 235-243, 2001.

57. Schmidt D, Textor B, Pein OT, et al: Critical role for NF-kappaBinduced JunB in VEGF regulation and tumor angiogenesis. EMBO J 26: 710-719, 2007

58. Imai T, Sakai M, Ohtake H, Azuma H and Otagiri M: Absorption-enhancing effect of glycyrrhizin induced in the presence of capric acid. Int J Pharm 294: 11-21, 2005. 